\title{
AUTONOMÍA DE LA VOLUNTAD Y SALUD MENTAL. MARCO NORMATIVO Y DESAFÍOS ACTUALES EN EL DERECHO ARGENTINO*
}

\author{
AUTONOMY OF WILL AND MENTAL HEALTH. NORMATIVE FRAMEWORK \\ AND CURRENT CHALLENGES IN THE ARGENTINIAN LAW
}

\author{
Rosalía MuÑoz Genestoux**
}

Resumen: El objetivo del artículo es analizar el régimen normativo en materia de salud Mental de la República Argentina, en lo concerniente a capacidad jurídica y a internaciones involuntarias por Salud Mental, desde una mirada de la autonomía de la voluntad y de los desafíos que la tensión entre ellas genera.

Palabras Clave: Autonomía de la voluntad, salud mental, capacidad jurídica, internación involuntaria.

Abstract: The objective of the article is to analyse the regulatory regime for the mental health of the Argentine Republic, regarding legal capacity and involuntary hospitalisations for mental health, from the perspective of the autonomy of the will and the challenges that the tension between them generate.

Key Words: Autonomy of the will, mental health, juridical capacity, involuntary internment.

SUMARIO: I. INTRODUCCIÓN; II. MARCO NORMATIVO EN EL DERECHO ARGENTINO; III. LIMITACION A LA CAPACIDAD Y AUTONOMÍA DE LA VOLUNTAD; IV. INTERNACIONES POR SALUD MENTAL; 1. Internaciones por padecimientos de salud mental; 2. Las internaciones por problemáticas de consumo de sustancias; V. CONCLUSIONES; VI. BIBLIOGRAFÍA.

* http://doi.org/10.15366/rjuam2018.38.012

Fecha de recepción: 5 de noviembre de 2018.

Fecha de aceptación: 19 de diciembre de 2018.

** Abogada. Especialista en Derecho de Familia de la Universidad de Buenos Aires. Docente de la materia «Derecho de Familia y Sucesiones» de la Universidad de Buenos Aires. Correo electrónico: rosaliamunoz@ gmail.com. Este artículo refleja los contenidos de la ponencia presentada en el Congreso Internacional «Desafíos actuales de la autonomía de la voluntad en las relaciones familiares y sus límites». Universidad Adolfo Ibáñez (Chile). Santiago de Chile 25 al 27 de septiembre 2018. 


\section{INTRODUCCIÓN}

El presente artículo intenta realizar un cruce entre el sistema legal en materia de Salud Mental existente en la República Argentina y el concepto de autonomía de la voluntad.

Comienzo por lo expresado por la magnífica jurista argentina Aida Kemelmajer de Carlucci que expresó: Desde esta perspectiva amplia, de algún modo, la autonomía se identifica con la libertad. Ha dicho la Corte Interamericana de Derechos Humanos que:

«El concepto de libertad y la posibilidad de todo ser humano de auto-determinarse y escoger libremente las opciones y circunstancias que le dan sentido a su existencia, conforme a sus propias opciones y convicciones, es un derecho humano básico, propio de los atributos de la persona, que se proyecta en toda la Convención Americana» ${ }^{1}$.

En este sentido se pretende diferenciar dos instancias donde la autonomía de la voluntad se cuestiona. Por un lado, los procesos de determinación de la capacidad jurídica; y por otro lado las internaciones involuntarias por padecimientos mentales, tanto de adultos, como de niños, niñas y adolescentes.

Analizaremos así estas instancias incluyendo los desafíos que plantean el régimen vigente y las prácticas que se realizan en el país desde la mirada de Derechos Humanos.

\section{MARCO NORMATIVO EN EL DERECHO ARGENTINO}

En principio, cabe señalar que el Preámbulo de la Convención sobre los Derechos de las Personas con Discapacidad -en adelante CDPD-, establece: «Reconociendo la importancia que para las personas con discapacidad reviste su autonomía e independencia individual, incluida la libertad de tomar sus propias decisiones...».

\footnotetext{
1 KEMELMAJER DE CARLUCCI, A., «La autonomía de la voluntad en el derecho de familia argentino. Versión actualizada con las modificaciones introducidas por el Código Civil y Comercial de la Nación», en GRAHAM, M. y HERRERA, M. (dirs.), Derecho de las familias, infancia y adolescencia: una mirada crítica y contemporánea, $1^{\mathrm{a}}$ ed., Buenos Aires (Infojus), 2015, p. 4. Disponible en <http:// www.saij.gob.ar/aida-kemelmajer-carlucci-autonomia-voluntad-derecho-familia-argentino-versionactualizada-modificaciones-introducidas-codigo-civil-comercial-nacion-dacf150750-2015-07/1234567890abc-defg 0570-51 fcanirtcod? \&o=15\&f=Total $\% 7 \mathrm{CFecha} / 2015 \% 5 \mathrm{~B} 20 \% 2 \mathrm{C} 1 \% 5 \mathrm{D} \% 7 \mathrm{CEstado} \% 20$ de $\% 20$ Vigencia $\% 5 \mathrm{~B} 5 \% 2 \mathrm{C} 1 \% 5 \mathrm{D} \% 7 \mathrm{CTema} /$ Derecho\%20civil/relaciones $\% 20 \mathrm{de} \% 20$ familia $\% 5 \mathrm{~B} 2 \% 2$ C1\%5D\%7COrganismo\%5B5\%2C1\%5D\%7CAutor\%5B5\%2C1\%5D\%7CJurisdicci\%F3n\%5B5\%2 C1\%5D\%7CTribunal\%5B5\%2C1\%5D\%7CPublicaci\%F3n\%5B5\%2C1\%5D\%7CColecci\%F3n\%20 tem\%E1tica\%5B5\%2C1\%5D\%7CTipo\%20de\%20Documento/Doctrina\&t=30 >. [Consultado el 14/10/2018].
} 
Más específicamente en su Art. 12 la CDPD dice en su inc. 2. ${ }^{\circ}$ : «Los Estados Partes reconocerán que las personas con discapacidad tienen capacidad jurídica en igualdad de condiciones con las demás en todos los aspectos de la vida».

Continúa en el Inc. $3^{\circ}$ : «Los Estados Partes adoptarán las medidas pertinentes para proporcionar acceso a las personas con discapacidad al apoyo que puedan necesitar en el ejercicio de su capacidad jurídica...».

De lo arriba citado es posible extraer así dos elementos importantísimos: el reconocimiento de capacidad jurídica a las personas con discapacidad en igualdad de condiciones de todas las personas en todas las áreas de su vida; y, la obligación de los Estados de establecer medidas positivas para proporcionar a aquellas personas con discapacidad que lo requieran el o los apoyo /s necesarios para poder realmente ejercer esa capacidad. Es decir, garantizar y generar las condiciones de posibilidad para la efectivización y concreción de dicha capacidad, con la mayor plenitud posible, o, en otras palabras, restituir a las personas con discapacidad poder tomar decisiones respecto a todos los aspectos de su vida.

Es, justamente, la CDPD el instrumento rector y base de la legislación argentina actual, aunque se deben nombrar diversos instrumentos que fueron guías de la regulación y de la práctica, como los Principios para la Protección de los Enfermos Mentales y para el mejoramiento de la Atención de la Salud Mental, aprobados por la Asamblea General de las Naciones Unidas en 1991 (resolución 46/119); la Declaración de Caracas; los Principios de Brasilia, rectores para el desarrollo de la atención de la Salud Mental en las Américas; Art. 21.12) de la Constitución de la Ciudad Autónoma de Buenos Aires; la Ley básica de salud de CABA 153/99; la Declaración Americana de los Derechos y Deberes del Hombre reconoce en su art. XI; la Declaración Universal de Derechos Humanos en su art. 25, 1); La Convención Americana de Derechos Humanos (Pacto de San José de Costa Rica) (art. 4.1 y (5.1); el Protocolo Adicional a la Convención Americana sobre Derechos Económicos, Sociales y culturales «Protocolo de San Salvador» (art. 1); el Pacto Internacional de Derechos Económicos, Sociales y Culturales (10.3); el Pacto internacional de Derechos Civiles y Políticos (art. 6.1 y 24.1), la Observación General 14 sobre el derecho a la salud (1994) del Comité de Derechos Económicos, Sociales y Culturales 1 y 22), etc.

La República Argentina suscribió la CDPD el 30/03/2007, la aprobó por ley 26.378 en el año 2008, la ratificó el 02/09/2008 y adquiere jerarquía constitucional mediante ley 27.044 -B.O. 22/12/2014.

En nuestro país, contamos con diversa normativa que fue adecuando el sistema, tanto legal, como sanitario, a los principios de la CDPD. Por ello, en el año 2010 se promulgó la Ley Nacional de Salud Mental N 26.657 (en adelante L.N.S.M), la que fue reglamentada por el Dcto 603/2013.

Esta Ley define a la salud Mental en su artículo 3ro como «un proceso determinado por componentes históricos, socio-económicos, culturales, biológicos y psicológicos, cuya 
preservación y mejoramiento implica una dinámica de construcción social vinculada a la concreción de los derechos humanos y sociales de toda persona. Se debe partir de la presunción de capacidad de todas las personas...».

Este artículo modifica sustancialmente un modelo de abordaje y ratifica los principios de la CDPD, al redefinir la concepción de la Salud Mental desde el modelo social de discapacidad.

Señala Agustina Palacios cuando expone su tesis del modelo social de discapacidad ${ }^{2}$ que:

«El modelo social presenta muchas coincidencias con los valores que sustentan a los derechos humanos; esto es: la dignidad, entendida como una condición inescindible de la humanidad; la libertad entendida como autonomía-en el sentido de desarrollo del sujeto moral-que exige entre otras cosas que la persona sea el centro de las decisiones que le afecten; y la igualdad inherente de todo ser humano -respetuosa de la diferencia-, la cual asimismo exige la satisfacción de ciertas necesidades básicas».

La aplicación de este modelo en la República Argentina implica una ponderación de la interdisciplina; de manera que queda habilitada en la práctica la consideración de los aportes desde diversas fuentes de saberes, así como la intervención de distintos agentes de la salud en un esfuerzo por sostener formas de abordaje más integrales. En otros términos, nuevos actores (psicólogas/os, trabajadoras/res sociales, terapistas ocupacionales, etc.), quienes intervenían anteriormente en los tratamientos de salud mental pero que carecían de la legitimación social, comienzan a introducir aspectos relevantes para la comprensión y la toma de decisiones relativas a la vida de las personas, en un ámbito donde los y las psiquiatras eran considerados los únicos autorizados para determinar, entre otras cosas, si una persona era o no capaz ${ }^{3}$.

Es, aún hoy, dificultoso en algunos ámbitos escapar a la lógica sanitarista o médico hegemónica. Pero algunas incorporaciones legislativas abrieron paso a distintos sectores de la sociedad que demandan y denuncian el cumplimiento de la ley, entre los que podemos destacar las asociaciones de pacientes.

Sumado a todo ello, el artículo establece que se parte de la presunción de capacidad de las personas, en consonancia con el art. 12 de la CDPD. De manera que, si todos y todas

2 PALACIOS, A., El modelo social de discapacidad: orígenes, caracterización y plasmación de la Convención Internacional sobre los Derechos de las Personas con Discapacidad, $1^{\circ}$ ed., Madrid (Grupo Editorial CINCA), 2008, p. 155.

3 El Código Procesal Civil de la Nación, establece aun hoy, que las evaluaciones que se realizaban para determinar la capacidad jurídica de una persona debía ser realizada por tres médicos psiquiatras o legistas, que deben informar sobre el estado actual de las facultades mentales del presunto insano. Es preciso destacar que en materia procesal el Código no ha sido actualizado aún. 
somos considerados capaces, podemos ejercer nuestros derechos y decidir, entre otras cosas, «de qué modo quiero vivir mi vida», lo que hace a la autodeterminación.

Con posterioridad a esta Ley, de la que más adelante vamos a proseguir comentando, nuestro país atraviesa un proceso de unificación de los Códigos Civil y Comercial, comenzando a regir en Argentina, el 1ro de agosto del 2015, el Código Civil y Comercial de la Nación (en adelante $\mathrm{CCyCN}$ ) que actualmente tiene vigencia.

Fue este $\mathrm{CCyCN}$ una oportunidad para adecuar nuestra norma a los principios internacionales en materia de Salud Mental y Derechos Humanos, evidenciándose el cambio de paradigma antes mencionado.

Señala María Graciela Iglesias, Secretaria Ejecutiva del Órgano de Revisión de Salud Mental Ley 26.657:

«El nuevo Código Civil y Comercial de la Nación ratificó y profundizó los postulados de la LNSM con una codificación abierta hacia las ventanas que representan algunas normas que son transversales a todo el derecho interno y que hacen a la constitucionalización del derecho privado, la aplicación de las convenciones, pactos y tratados internacionales ratificados por el Estado, así como contar con norma expresa respecto de la dignidad de las personas y su inviolabilidad, esto necesariamente atraviesa en el tratamiento jurídico de las personas con padecimientos mentales, en las internaciones y las restricciones a la capacidad jurídica» ${ }^{4}$.

Es así, que el artículo 22 de la norma de fondo establece: «Toda persona humana goza de la aptitud para ser titular de derechos y deberes jurídicos. La ley puede privar o limitar esta capacidad respecto de hechos, simples actos, o actos jurídicos determinados». Continuando el siguiente artículo: «Toda persona humana puede ejercer por sí misma sus derechos, excepto las limitaciones expresamente previstas en este Código y en una sentencia judicial».

Tal como expresa Silvia Fernández ${ }^{5}$ respecto a la capacidad de hecho y de derecho en el Código Civil:

«...es dable destacar un instrumento internacional de derechos humanos básico y central en el campo de salud mental como lo es la Convención sobre los Derechos de las Personas con Discapacidad (CDPD), el que se elaboró dentro del marco

\footnotetext{
4 IGLESIAS, M. G., «La Ley Nacional de Salud Mental, el Código Civil y Comercial y las leyes provinciales» en Derecho de Familia. Revista interdisciplinaria de Doctrina y Jurisprudencia, núm. 77, 2016, Buenos Aires, p. 99.

5 FERNANDEZ, S., «Comentario al Art. 22», en HERRERA, M.; CARAMELO, G. y PICASSO, S. (dirs.), Código Civil y Comercial de la Nación comentado, 1. a ed., 2015, Buenos Aires (Infojus), p. 55.
} 
de los derechos humanos, tomando el aspecto filosófico del modelo social de la discapacidad, para el cual la discapacidad es una construcción resultante de una sociedad "que no considera ni tiene presente a las personas con discapacidad"; lo que este modelo propugna es la eliminación de cualquier tipo de barreras sociales y materiales para fortalecer, precisamente, la autonomía y la toma de decisiones propias, con el fin de equiparar oportunidades. Por lo que la restricción a la capacidad, bajo determinados supuestos que establece la ley, debe entenderse que es con la finalidad de posibilitar y fortalecer el ejercicio de la capacidad jurídica de las personas con discapacidad, para lo cual se nombrarán apoyos y salvaguardias, como lo establece la CDPD».

Por su parte, el articulo $26 \mathrm{CCyCN}^{6}$ determina de qué forma ejercen los derechos las personas menores de edad. Señalando la diferencia entre los adolescentes de 13 a 16 años y los mayores de 16 años, siendo estos últimos como adultos para las decisiones atinentes al cuidado de su propio cuerpo.

En relación con el modo en el que el CCyCN previó la regulación relativa a los adolescentes debemos señalar que lo hizo atendiendo al principio de capacidad progresiva de la $\mathrm{CDN}$ y de la Ley 26.061. Es en atención a ello que los jóvenes pueden tomar decisiones respecto a sus tratamientos terapéuticos siempre que no importen un riesgo para su vida o una situación de salud de gravedad ${ }^{7}$.

En esta instancia debemos distinguir de qué tipo de tratamiento se trata y qué requerimiento respecto del consentimiento informado tiene. En principio para lo que es tratamiento

\footnotetext{
${ }^{6}$ Art. 26 CCyCN: Ejercicio de los derechos por la persona menor de edad. La persona menor de edad ejerce sus derechos a través de sus representantes legales.

No obstante, la que cuenta con edad y grado de madurez suficiente puede ejercer por sí los actos que le son permitidos por el ordenamiento jurídico. En situaciones de conflicto de intereses con sus representantes legales, puede intervenir con asistencia letrada.

La persona menor de edad tiene derecho a ser oída en todo proceso judicial que le concierne, así como a participar en las decisiones sobre su persona.

Se presume que el adolescente entre trece y dieciséis años tiene aptitud para decidir por sí respecto de aquellos tratamientos que no resultan invasivos, ni comprometen su estado de salud o provocan un riesgo grave en su vida o integridad física.

Si se trata de tratamientos invasivos que comprometen su estado de salud o está en riesgo la integridad o la vida, el adolescente debe prestar su consentimiento con la asistencia de sus progenitores; el conflicto entre ambos se resuelve teniendo en cuenta su interés superior, sobre la base de la opinión médica respecto a las consecuencias de la realización o no del acto médico.

A partir de los dieciséis años el adolescente es considerado como un adulto para las decisiones atinentes al cuidado de su propio cuerpo.

7 Para profundizar sobre este tema, FERNANDEZ, S.; HERRERA, M. y LAMM, E., El principio de autonomía progresiva en el campo de la salud, Buenos Aires (La Ley), 2017. Disponible en <http:// thomsonreuterslatam.com/2017/11/el-principio-de-autonomia-progresiva-en-el-campo-de-la-salud/>. [Consultado el 23/10/18].
} 
terapéutico, estudios de detección o diagnostico relativos a la salud mental, prescripción de tratamiento farmacológico, encuadran en la autonomía prevista en el art. 26 del $\mathrm{CCyCN}^{8}$.

En relación con las internaciones por salud mental, independientemente de procurarse el consentimiento informado de las/os adolescentes y tal como ampliaremos más adelante, deben considerarse como internaciones involuntarias a los efectos del control judicial.

\section{LIMITACIÓN A LA CAPACIDAD Y AUTONOMÍA DE LA VOLUNTAD}

Tal como he expuesto al inicio de esta presentación es, en la restricción a la capacidad jurídica, donde observamos una limitación al principio de autonomía de la voluntad, dado que una persona puede potencialmente ejercerla en tanto y en cuanto no se vea limitada por una sentencia que la restrinja.

Ahora bien, estas limitaciones tienen reglas generales que se encuentran previstas en el artículo 31 del CCyCN9.

Podemos señalar entre las más importantes que la capacidad de ejercicio se presume; que las limitaciones son de carácter excepcional y se imponen en beneficio de la persona; $\mathrm{y}$, que la persona tiene derecho a participar con asistencia letrada en los procesos donde se determina su capacidad.

El CCyCN dispone en su artículo 32 que la capacidad puede ser restringida a toda persona mayor de 13 años, es decir a los/as adultos/as y a los/as adolescentes.

Se puede restringir siempre que la persona padezca una adicción o una alteración mental permanente o prolongada, de suficiente gravedad, siempre que considere que, del ejercicio de su plena capacidad, que es la regla, puede resultar un daño a su persona o a sus bienes.

Asimismo, circunscribe los casos excepcionales de incapacidad en su último párrafo donde determina que «Cuando la persona se encuentre absolutamente imposibilitada de interaccionar con su entorno y expresar su voluntad por cualquier modo, medio o formato adecuado y el sistema de apoyos resulte ineficaz...».

\footnotetext{
8 Para profundizar sobre el tema, FERNANDEZ, S., «Adolescencia y salud mental. Vulnerabilidad y ejercicio de los derechos a la luz del principio de autonomía progresiva», Derecho de Familia. Revista Interdisciplinaria de Doctrina y Jurisprudencia, núm. 77, 2016, pp.163 y ss.

9 Artículo $31 \mathrm{CCyCN}$. Reglas generales. La restricción al ejercicio de la capacidad jurídica se rige por las siguientes reglas generales: a. la capacidad general de ejercicio de la persona humana se presume, aun cuando se encuentre internada en un establecimiento asistencial: b. las limitaciones a la capacidad son de carácter excepcional y se imponen siempre en beneficio de la persona; c. la intervención estatal tiene siempre carácter interdisciplinario, tanto en el tratamiento como en el proceso judicial; $d$. la persona tiene derecho a recibir información a través de medios y tecnologías adecuadas para su comprensión; e. la persona tiene derecho a participar en el proceso judicial con asistencia letrada, que debe ser proporcionada por el Estado si carece de medios; f. deben priorizarse las alternativas terapéuticas menos restrictivas de los derechos y libertades.
} 
Haciendo un análisis del CCyCN el Dr. Francisco Bariffi remarca: «... establece un régimen de limitaciones a la capacidad jurídica que es "lineal" y no "paralelo". Es decir, se decanta por una primera opción menos restrictiva denominada "capacidad restringida" y solo en caso de "ineficacia" del sistema de apoyo se establece una segunda opción de "incapacidad" con curatela» ${ }^{10}$.

Es importante señalar que el $\mathrm{CCyCN}$ reconoce a la persona con discapacidad su carácter de «parte» colocándola en un lugar de poder llevar adelante los actos procesales reconocidos en el ordenamiento, pero esto se dificulta, tal como señala la Dra. Sarquis ${ }^{11}$, dado que esta participación se reduce a «la audiencia previa al dictado de la sentencia».

Señala la Dra. Palacios, experta en la materia, que: «El derecho a contar con asistencia letrada es un elemento constitutivo del derecho de acceso a la justicia y una garantía básica del debido proceso, que han visto vulneradas las personas con discapacidad mental, entre otras razones como derivación de lo descripto respecto de sus dificultades para ser consideradas "parte" en el proceso .... ${ }^{12}$.

Respecto de la posibilidad de presentar prueba que se le otorga a la persona en su carácter de parte en el proceso, el CCyCN modificó el criterio del Código Procesal Civil y Comercial de la Nación (en adelante $\mathrm{CPCCN}$ ) ${ }^{13}$ estableciendo uno más amplio y no tan restringido como el que disponía el código de forma ${ }^{14}$.

En los casos en los que se limite la capacidad de la persona para determinados actos, los mismos, deben estar especificados en la sentencia procurando la menor afectación posible a la autonomía personal. En dichas situaciones se requerirá para la realización de los actos jurídicos de la figura de «apoyo». Definimos apoyo conforme el Articulo 43 del CCyCN como:

10 BARIFFI, F., «Restricción a la capacidad y capacidad civil. Tensiones constitucionales y Código Civil y Comercial», Derecho de Familia. Revista Interdisciplinaria de Doctrina y Jurisprudencia, núm. 77, 2016, p. 65 .

11 SARQUIS. L., «Las personas con discapacidad y su participación en el proceso de determinación de la capacidad ¿obstáculos diferenciados en su perjuicio?», Derecho de Familia. Revista Interdisciplinaria de Doctrina y Jurisprudencia, núm. 84, 2018, p. 129.

12 PALACIOS, A., «A modo de introducción. La Salud Mental como cuestión de Derechos Humanos», en HERRERA, M.; LLOVERAS, N. y KEMELMAJER DE CARLUCCI, A. (dirs.), Máximos Precedentes. Derecho de Familia, Tomo IV, Buenos Aires, (La Ley), 2014, p. 754.

13 Código Procesal Civil y Comercial de la Nación. Este CPCCN no fue aun modificado, razón por la cual toda la normativa de forma respecto de los procesos de restricción de capacidad no son armónicas con el ordenamiento de fondo.

14 Para ampliar, BUDICH, M.; FERRAIUOLO, A., «Los procesos sobre determinación de la capacidad jurídica; necesidad de armonizar la normativa de forma y de fondo», Revista del Ministerio Publico de la Nación, núm. 11, 2016. Disponible en <https://www.mpd.gov.ar/pdf/publicaciones/revista/Revista\%20MPD\%202016. pdf $>$. [Consultado el 23/10/18]. 
«Se entiende por apoyo cualquier medida de carácter judicial o extrajudicial que facilite a la persona que lo necesite la toma de decisiones para dirigir su persona, administrar sus bienes y celebrar actos jurídicos en general.

Las medidas de apoyo tienen como función la de promover la autonomía y facilitar la comunicación, la comprensión y la manifestación de voluntad de la persona para el ejercicio de sus derechos».

Más profundamente la Dra. Iglesias analiza la noción de apoyo en el marco de la CDPC y dice: «El apoyo al que hace referencia el art. 12 de la CDPD alude a aquella persona, organismo, allegado, institución que a través de la comprensión y la confianza de la persona, colabora para la toma de decisiones y con la manifestación del ejercicio de la capacidad jurídica» ${ }^{15}$.

Es decir que, en términos de autonomía de la voluntad, la misma persiste tanto como la persona a quien se restringe su capacidad pueda manifestar con mayor claridad su voluntad y sus intereses, dado que el «apoyo» tiene como función «colaborar» con la toma de decisiones, pero no decidir por la persona.

Es esencial distinguir que no es una figura que tiene por objeto la «protección», en el sentido del modelo tutelar superado, sino que tiene por objeto reconocer y garantizar los derechos de la persona y facilitar la toma de decisiones en clave de autodeterminación.

Asimismo, podemos distinguir esos apoyos «formales», necesarios en muchos casos para la concreción de actos jurídicos, de los apoyos «informales», estos, dedicados a la concreción de actos de la vida cotidiana de la persona. En ellos no se controvierte la autonomía de la voluntad y colaborarán de acuerdo a las necesidades diarias de cada persona. A diferencia de los apoyos formales, estos no requerirán jurisdicción.

\section{INTERNACIONES INVOLUNTARIAS POR SALUD MENTAL}

\section{Internaciones por padecimientos de salud mental}

Otro aspecto en el que nos vamos a detener y donde se pone en juego la autonomía de la voluntad es en las internaciones involuntarias ${ }^{16}$ por problemáticas de salud mental o consumo problemático de sustancias psicoactivas. Si bien, en ambos casos el abordaje es

\footnotetext{
15 IGLESIAS, M.G., «La capacidad jurídica. El modelo de apoyo en la toma de decisiones», en ZITO FONTÁN, O. (coord.), Hacia un nuevo concepto de capacidad jurídica, 1. a ed., Buenos Aires (Ad-Hoc), 2014, p. 69.

${ }_{16}$ Decimos que solo en las internaciones involuntarias, porque está previsto en el ordenamiento la posibilidad de internarse voluntariamente, pero a diferencia de las involuntarias una persona que opto por ingresar a un dispositivo de internación puede decidir en qué momento retirarse del mismo, es decir no se advierte restringida la autonomía de la voluntad.
} 
conforme lo establece la LSMN, dadas algunas cuestiones que se advierten en la práctica, principalmente en relación a las políticas públicas destinadas a paliar dichos padecimientos, se torna necesario distinguirlas.

En primer término, debemos definir que entendemos por internación involuntaria. Según lo establece el artículo 20 de la LNSM, «la internación involuntaria de una persona debe concebirse como recurso terapéutico excepcional en caso de que no sean posibles los abordajes ambulatorios, y solo podrá realizarse cuando a criterio del equipo de salud mediare situación de riesgo cierto e inminente para sí o para terceros...».

¿Qué es «riesgo cierto e inminente»? Es la contingencia o proximidad de un daño que ya es conocido como verdadero, seguro e indubitable que amenace o cause perjuicio a la vida o integridad física de la persona o de terceros.

Se realiza por evaluación actual del equipo interdisciplinario y no puede reducirse a un diagnóstico o clasificación.

Se entiende entonces, que se considerará internación involuntaria a aquella en la que la persona no haya prestado su consentimiento informado, ya sea porque no es su voluntad o por la imposibilidad de prestarlo; los casos donde tenga restringida su capacidad a tal fin; cuando el consentimiento informado sea suscripto por un representante legal; y en todos los casos de niños, niñas y adolescentes.

El artículo 26 de la LNSM establece: «En caso de internación de personas menores de edad o declaradas incapaces, se debe proceder de acuerdo a lo establecido por los artículos 20, 21, 22, 23, 24 y 25 de la presente ley. En el caso de niños, niñas y adolescentes, además se procederá de acuerdo a la normativa nacional e internacional de protección integral de derechos».

¿Por qué decimos entonces que la internación es una instancia donde la autonomía de la voluntad se presenta en tensión y cede ante la situación de riesgo cierto e inminente?

Básicamente, porque tal como lo establece el artículo, en los casos donde un equipo interdisciplinario, luego de una evaluación, considere que una persona está en situación de riesgo cierto e inminente para sí o para terceros, no requiere de su manifestación de voluntad para disponer la internación ${ }^{17}$.

Esta internación, tal como lo dice la LNSM deberá ser comunicada al Órgano jurisdiccional en un plazo máximo de 10 horas $^{18}$ y se procederá a iniciar las actuaciones judiciales

17 Esto no significa que el equipo tratante no deba en los términos de la Ley del Paciente procurar el consentimiento informado de la persona.

18 Artículo 21 Ley 26.657: «La internación involuntaria debidamente fundada debe notificarse obligatoriamente en un plazo de diez horas al juez competente y al órgano de revisión, debiendo agregarse a las cuarenta y ocho horas como máximo todas las constancias previstas en el artículo 20. El juez en un plazo máximo de tres días corridos de notificado debe:

a) Autorizar, si evalúa que están dadas las causales previstas por esta ley; 
de «control de internación». La internación será revisada periódicamente; deberá ser entendida de modo excepcional, dado lo cual si existiere algún tipo de intervención o tratamiento menos restrictivo de la libertad debería modificarse.

Por otro lado, se debe garantizar el debido proceso, el control judicial y el derecho de toda persona a ser asistido por un/a letrado/a.

El artículo 22 de la LNSM - «La persona internada involuntariamente o su representante legal, tiene derecho a designar un abogado. Si no lo hiciera, el Estado debe proporcionarle uno desde el momento de la internación. El defensor podrá oponerse a la internación y solicitar la externación en cualquier momento. El juzgado deberá permitir al defensor el control de las actuaciones en todo momento».

¿Cuál es la función del abogado según el art. 22 de la LSMN?

El art. 22 del Decreto 603/13 establece que en el ejercicio de la asistencia técnica el abogado defensor debe respetar la voluntad y las preferencias de la persona internada -sin conflicto de intereses-, en lo relativo a su atención y tratamiento.

En la Ciudad de Buenos Aires, la Defensoría General de la Nación creó dos Unidades de Letrados (art. 22 Ley 26.657), una de adultos y una de niño, niñas y adolescentes que tienen por función ejercer la defensa técnica de usuarios de los servicios de salud mental, que estén internados de manera involuntaria y no hayan designado un/a abogado/a defensor/a en forma privada.

Estos/as letrados/as se constituyen en la clínica, hospital monovalente o polivalente, comunidad terapéutica, donde se encuentren alojados/as los/as usuarios/as con el objeto de conocer su voluntad e intereses y trasladarla al Juzgado Nacional Civil con competencia exclusiva en cuestiones de Familia, que controla dicha internación ${ }^{19}$.

Cobra gran importancia la intervención de abogados/as en las internaciones involuntarias de las personas, especialmente porque el/la abogado/a interviniendo lo hace en el carácter de abogado/a de parte, es decir, va a solicitar lo necesario para la externación de su defendido/a conforme este lo solicite.

b) Requerir informes ampliatorios de los profesionales tratantes o indicar peritajes externos, siempre que no perjudiquen la evolución del tratamiento, tendientes a evaluar si existen los supuestos necesarios que justifiquen la medida extrema de la internación involuntaria y/o;

c) Denegar, en caso de evaluar que no existen los supuestos necesarios para la medida de internación involuntaria, en cuyo caso debe asegurar la externación de forma inmediata.

El juez solo puede ordenar por sí mismo una internación involuntaria cuando, cumplidos los requisitos establecidos en el artículo 20, el servicio de salud responsable de la cobertura se negase a realizarla».

19 Cabe destacar que la única jurisdicción donde un organismo creo específicamente un cuerpo de abogadas/ os para realizar esta tarea fue en la Ciudad Autónoma de Buenos Aires, siendo ejercida en otras jurisdicciones por distintos actores a quienes se les encomienda la función. 
Señala Luz Pagano respecto de la función del abogado del art. 22 Ley $26.657^{20}: \ll \ldots$ El defensor ejerce una defensa técnica y pesa sobre este el deber de representar al paciente, incluso en todo procedimiento de queja o apelación». Continúa diciendo: «...en el ejercicio de la asistencia técnica el abogado defensor debe respetar la voluntad y las preferencias de la persona internada...».

Con fecha 12 de octubre del 2018 el Comité de Derechos Económicos, Sociales y Culturales dio las Observaciones finales sobre el cuarto informe periódico de Argentina ${ }^{21}$ y señaló:

«El Comité nota que, con base en la Ley Nacional de Salud Mental (2010), el Estado parte se comprometió a transformar el sistema de salud mental y cerrar los manicomios antes del 2020. No obstante, el Comité está preocupado que el encierro en instituciones psiquiátricas sigue siendo la principal respuesta del Estado en materia de salud mental. Preocupa también al Comité las condiciones de vida estas instituciones de personas internadas y la muy fuerte reducción del presupuesto asignado a la Dirección Nacional de Salud Mental incumpliendo con la pauta fijada por la Ley Nacional de Salud Mental ( $10 \%$ del gasto en salud) (art. 12)».

Asimismo, dentro de las recomendaciones señaló entre otras:

«(c) Garantizar de que los tratamientos se administran sobre la base de un consentimiento libre e informado;

(d) Promover en todo el país la defensa técnica especializada para personas internadas en forma involuntaria para que su caso sea revisado regularmente;

(e) Concretar en 2020 la sustitución del sistema de instituciones psiquiátricas de salud mental públicas y privadas por un sistema de integral, integrado, interdisciplinario y comunitario de Salud Mental, en cumplimiento del Plan Nacional de Salud Mental.

(f) Propiciar que niños y adolescentes sean atendidos en forma comunitaria, priorizando la atención ambulatoria, domiciliaria y en la zona de arraigo, y se restrinja la institucionalización...».

Estas sugerencias del Comité cobran vital importancia si tenemos en cuenta que, en la Ciudad de Buenos Aires, un gran número de niños, niñas y adolescentes cursan internaciones por padecimientos en su salud mental en hospitales, clínicas y comunidades terapéuticas. Y entre otras cosas, es importante trabajar y profundizar esta problemática, porque justamente

\footnotetext{
20 PAGANO, L., «Internaciones por causa de salud mental», en Revista de Actualidad Derecho de Familia en el Código Civil y Comercial, núm. 6, 2017, p.183.

${ }_{21}$ Disponible en $<$ https://tbinternet.ohchr.org/layouts/treatybodyexternal/Download.aspx?symbolno=E/C.12/ $\mathrm{ARG} / \mathrm{CO} / 4 \&$ Lang=en $>$. [Compulsada 03/11/18].
} 
es en estos casos donde el derecho otorga un plus de garantías en atención a su calidad de personas en desarrollo, advirtiéndose diversos derechos que se ven afectados al permanecer en una institución. Claramente se ve afectado el derecho a vivir con su familia, a la educación, al esparcimiento, entre otros, todos ellos de raigambre constitucional.

Es preciso advertir que muchos de los/las adolescentes que tienen padecimiento en su salud mental o consumo problemático de sustancias viven en situación de mucha precariedad, con escasos recursos económicos y en muchos casos desvinculados de sus familias o con poca vinculación con ellas, alojándose en virtud de la normativa local de protección de derechos en hogares convivenciales y de atención especializada.

Es muy interesante un análisis que realiza Michalewicz ${ }^{22}$ :

«Las demandas de atención en salud mental que surgen de los hogares convivenciales y de atención especializada tienen que ver con problemáticas que si bien implican a este grupo de niños/as altos grados de sufrimiento psíquico, difícilmente puedan abordarse desde las categorías psicopatológicas tradicionales. Podrían enmarcarse en lo que Galende ha definido como "nuevas demandas en salud mental" las cuales se encuentran íntimamente relacionadas con las dinámicas de integración-exclusión social y ponen en evidencia la limitación de las solas acciones de salud mental para abordarlas».

Asigna Barcala ${ }^{23}$ al Sistema de Salud Mental de la Ciudad de Buenos Aires en las últimas décadas «escasez de una racionalidad organizativa en términos sanitarios, ausencia de planificación de políticas específicas de niñez que garanticen los cuidados de atención de los niños, niñas y adolescentes, inexistente asignación de recursos...».

En conclusión, tal como propusimos es necesario un profundo trabajo desde los dispositivos de salud y desde el resto de las áreas que deben gestar políticas públicas adecuadas.

En el campo práctico de trabajo, se evidencia la confluencia de factores de diversos órdenes mostrando que resulta insuficiente abordar las problemáticas de salud mental solo desde la mirada médica-psiquiátrica.

Esta complejidad conlleva un tratamiento integral con el objetivo principal de favorecer los abordajes comunitarios, generar redes de contención y potenciar dispositivos sociales alternativos que superen la institucionalización como recurso necesario. Encontramos en

22 MICHALEWICZ, A., «Atención en Salud Mental de los niños, niñas y adolescentes alojados en hogares (Ongs) en la Ciudad de Buenos Aires. Problemáticas complejas e intervenciones posibles a partir de la articulación intersectorial», en BLANCK, E., Dialogo Abierto acerca del Estado de implementación de la Ley 26061, Buenos Aires (Eudeba), 2011, p. 10.

23 BARCALA, A., «Sufrimiento psicosocial en la niñez; el desafío de las políticas en Salud Mental». Disponible en $<$ https://gruposaludmentalfts.files.wordpress.com/2014/02/barcalasufrimiento_psicosocial_en_ la_nic3b1ez.pdf $>$. [Consultado el 03/11/18]. 
estas formas alternativas una correspondencia con el principio de autonomía de la voluntad de niñas, niños y adolescentes.

\section{Las internaciones por problemáticas de consumo de sustancias}

Tal como se ha expuesto, la LNSM establece que: «Las adicciones deben ser abordadas como parte integrante de las políticas de salud mental ${ }^{24} \gg$. Su decreto reglamentario Dec. 603/13 por su parte dice: «Desde una perspectiva de salud integral... y el eje deberá estar puesto en la persona en su singularidad».

Si bien, la norma es clara, las dificultades en Argentina se generan en la práctica; en el modo en el que se abordan las problemáticas de consumo, tanto de adultos como de niños, niñas y adolescentes, y más visiblemente entre quienes se encuentran desfavorecidos económicamente y en situaciones de vulnerabilidad.

En una primera instancia, porque la ley aborda las adicciones o consumo problemático de sustancias desde el modelo de reducción de riesgos y daños, modelo que se ha extendido a nivel mundial y que entre otras características:

«La reducción de daños -en algunos países llamada reducción del riesgo o minimización de los daños- es una estrategia de abordaje de los daños potenciales relacionados con el uso de drogas.

Tiene como primer objetivo disminuir los efectos negativos producto del uso de drogas, y a partir de allí, construir conjuntamente con el sujeto que demanda objetivos de mayor complejidad, con el fin de mejorar la calidad de vida de los usuarios de drogas.

Las estrategias de reducción de daños se han ocupado no solo de las prácticas individuales de los usuarios de drogas, sino de comprender las condiciones de vulnerabilidad de los sujetos para desarrollar intervenciones apropiadas, y establecer relaciones específicas de cuidado y reciprocidad entre los individuos y los grupos en los contextos de uso de drogas.

Algunos programas de reducción de daños desarrollan acciones para involucrar a otros habitantes del territorio en el que intervienen (vecinos, militantes sociales o instituciones públicas como las escuelas o los centros de atención sanitaria) en la transformación de situaciones de padecimiento que los afectan $»^{25}$.

Paradojalmente, la modalidad de tratamiento en clínicas, hospitales y comunidades terapéuticas responde habitualmente al modelo abstencionista, modelo al que podríamos cuestionar, en cierta medida porque requiere la voluntad de no consumir, la que muchas

24 Articulo 4 Ley 26.657.

25 Disponible en $<$ http://intercambios.org.ar/es/que-es-reduccion-de-danos/>. [Consultado el 04/11/18]. 
veces no se obtiene de un día para el otro, sino que requiere de un gran trabajo terapéutico que en contados casos se realiza.

En el año 2014 se evidencia la compleja problemática en materia de salud mental y adicciones, a partir del dictado de la Ley 26.934 Plan Integral para el abordaje de los consumos problemáticos, del año 2014 que dice en su artículo 9: «Los consumos problemáticos deben ser abordados como parte integrante de las políticas de salud mental».

Entre las pautas que el artículo 10 establece podemos remarcar el respetar la autonomía individual y la singularidad que los sujetos demandan para el tratamiento de abuso de sustancias y adicciones; procurar el abordaje ambulatorio, siendo la internación el recurso terapéutico restrictivo y extremo; incorporar el modelo de reducción de riesgos y daños.

La citada ley dispone asimismo que, en los casos en los que los sujetos se encuentren en una situación de vulnerabilidad social que atente contra el pleno desarrollo de sus capacidades, el Estado debe incluirlos en "dispositivos especiales" de integración. Esa fase de integración tiene dos componentes, el educativo y el laboral» ${ }^{26}$.

De la observación de la práctica, es muy complicado el abordaje de las problemáticas de consumo en esa tensión que remarcábamos se presenta en relación a la autonomía de la voluntad, porque en casos de consumo de muchos años la valoración del «riesgo cierto e inminente» que realizan los equipos interdisciplinarios también difiere; lo cual provoca que muchas veces, en las guardias de los hospitales se realice una desintoxicación pero no se trabaje la continuidad de un tratamiento terapéutico luego de la externación. Esto deviene necesariamente en la continuidad del consumo y se repite en el tiempo, encontrándose más comprometidos en cuanto a su salud integral.

Respecto de niños, niñas y adolescentes (NNyA), la situación es más grave aún, dado que en general carecen de referentes afectivos que puedan ayudarlos a sostener tratamientos en forma ambulatoria, en muchos casos se encuentran en situación de calle, alternando algunas veces con paradores estatales y exponiendo a situaciones de riesgo con personas adultas. Señala la Dra. Folgar, quien coordina la Unidad de Letrados de Personas Menores de Edad (art. 22 Ley 26.657 de la Defensoría Gral. de la Nación): «Cada vez que el NNyA llega a una nueva internación, procurando por lo general -por lo menos así nos manifiestan-sortear la problemática en la que se encuentra sumergido, poco -y en algunos casos nada- permanecen en los dispositivos que debieran brindarle tratamiento integral; volviendo a la situación de calle, hasta reingresar en una nueva internación» ${ }^{27}$.

26 FOLGAR, M. L. y MUÑOZ GENESTOUX, R., «Vulnerables e invisibles: chicos en situación de calle y consumo problemático», Derecho de Familia. Revista interdisciplinaria de Doctrina y Jurisprudencia, núm. 84, 2018, p. 51.

27 FOLGAR, M. L., «Consumo problemático de sustancias psicoactivas de NNyA en situación de calle. Vulnerabilidad extrema: tensión entre el discurso jurídico y la realidad», Revista del Ministerio Publico de la Nación, núm. 11, 2016, p. 82. Disponible en <https://www.mpd.gov.ar/pdf/publicaciones/revista/Revista\%20 MPD\%202016.pdf>. [Consultado el 23/10/18]. 
Este ítem en particular merece una constante revisión, dado que en numerosas ocasiones nos topamos con realidades que nos enfrentan a contradicciones o situaciones paradojales; a los límites de nuestra conceptualización y nuestras posibilidades de dar respuestas en la práctica.

\section{CONCLUSIONES}

El principio de autonomía de la voluntad es transversal a todo el ordenamiento en materia de familia en la República Argentina, y especialmente en lo relacionado a las problemáticas de salud mental y consumo problemático de sustancias.

El marco regulatorio local, dado especialmente por el CCyCN y la LNSM, se encuentra robustecido por la CDPD y demás instrumentos de derechos humanos con jerarquía constitucional.

En ellos se reconoce a toda persona con discapacidad la posibilidad de tomar sus propias decisiones, en igualdad de condiciones que el resto de las personas y a ser asistidas por una persona de su confianza para aquellos actos en los que requiera de un «apoyo» para la toma de decisiones, siempre haciendo prevalecer su voluntad.

Por otro lado, es en las internaciones involuntarias donde está en juego el principio que nos convoca, y donde el mismo se ve afectado si ponderamos este derecho, con el derecho a la vida y la integridad psicofísica, que se busca resguardar ante las situaciones de riesgo cierto e inminente que se han descripto.

Más compleja aún se torna la situación de las personas con consumo problemático de sustancias para quienes los recursos son escasos y no atienden la problemática desde el modelo de reducción de daños necesariamente.

En definitiva, desde el paradigma social de discapacidad, teniendo en cuenta nuestra legislación, se ve plasmado el reconocimiento de la autonomía de la voluntad de las personas con discapacidad adultas y menores de edad, con las particularidades expuestas en cada caso, aunque observamos aun cierta resistencia en materia de políticas públicas que acompañen a las personas con discapacidad, faciliten la toma de decisiones y acerquen a los usuarios políticas públicas adecuadas y suficientes con el objeto de garantizar su derecho a la autodeterminación.

\section{BIBLIOGRAFÍA}

BARCALA, A., «Sufrimiento psicosocial en la niñez; el desafío de las políticas en Salud Mental». Disponible en <https://gruposaludmentalfts.files.wordpress. com/2014/02/barcala-sufrimiento_psicosocial_en_la_nic3blez.pdf $>$. [Consultado el 03/11/18]. 
BARIFFI, F., «Restricción a la capacidad y capacidad civil. Tensiones constitucionales y Código Civil y Comercial», Derecho de Familia. Revista Interdisciplinaria de Doctrina y Jurisprudencia, núm. 77, 2016 pp. 57-73.

BUDICH, M. y FERRAIUOLO, A., «Los procesos sobre determinación de la capacidad jurídica; necesidad de armonizar la normativa de forma y de fondo», Revista del Ministerio Publico de la Nación, núm. 11, pp. 111-120. Disponible en $<$ https://www.mpd.gov.ar/pdf/publicaciones/revista/Revista\%20MPD\%202016. pdf $>$. [Consultado el 23/10/18].

FERNANDEZ, S., «Comentario al Art. 22», en HERRERA, M.; CARAMELO, G. y PICASSO, S. (dirs.), Código Civil y Comercial de la Nación comentado, 1. ${ }^{\mathrm{a}}$ ed., Buenos Aires (Infojus), 2015, pp. 55-57.

FOLGAR, M. L., «Consumo problemático de sustancias psicoactivas de NNyA en situación de calle. Vulnerabilidad extrema: tensión entre el discurso jurídico y la realidad», Revista del Ministerio Publico de la Nación, núm. 11, 2016, pp. 81-90. Disponible en $<$ https://www.mpd.gov.ar/pdf/publicaciones/revista/Revista\%20 MPD\%202016.pdf >. [Consultado el 23/10/18].

FOLGAR, M. L. y MUÑOZ GENESTOUX, R., «Vulnerables e invisibles: chicos en situación de calle y consumo problemático» en Derecho de Familia», Revista interdisciplinaria de Doctrina y Jurisprudencia, núm. 84, 2018, pp. 49-63.

IGLESIAS, M. G., «La Ley Nacional de Salud Mental, el Código Civil y Comercial y las leyes provinciales», Derecho de Familia. Revista interdisciplinaria de Doctrina y Jurisprudencia, núm. 77, 2016, pp. 97-112

IGLESIAS, M. G., «La capacidad jurídica. El modelo de apoyo en la toma de decisiones», en ZITO FONTÁN, O. (coord..), Hacia un nuevo concepto de capacidad

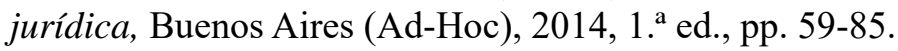

KEMELMAJER DE CARLUCCI, A., «La autonomía de la voluntad en el derecho de familia argentino. Versión actualizada con las modificaciones introducidas por el Código Civil y Comercial de la Nación», en GRAHAM, M. y HERRERA, M. (dirs.), Derecho de las familias, infancia y adolescencia: una mirada crítica y contemporánea, 1. a ed., Buenos Aires (Infojus), 2015, pp. 3-42. Disponible en $<$ http://www.saij.gob.ar/aida-kemelmajer-carlucci-autonomia-voluntadderecho-familia-argentino-version-actualizada-modificaciones-introducidascodigo-civil-comercial-nacion-dacf150750-2015-07/123456789-0abc-defg057051 fcanirtcod? \&o=15\&f=Total $\% 7 \mathrm{CFech} / 2015 \% 5 \mathrm{~B} 20 \% 2 \mathrm{C} 1 \% 5 \mathrm{D} \% 7 \mathrm{CEstado} \% 20$ de $\% 20$ Vigencia $\% 5 \mathrm{~B} 5 \% 2 \mathrm{C} 1 \% 5 \mathrm{D} \% 7 \mathrm{CTema} /$ Derecho\%20civil/relaciones $\% 20$ de $\% 20$ familia $\% 5 \mathrm{~B} 2 \% 2 \mathrm{C} 1 \% 5 \mathrm{D} \% 7 \mathrm{COrganismo} \% 5 \mathrm{~B} 5 \% 2 \mathrm{C} 1 \% 5 \mathrm{D} \% 7 \mathrm{CAut}$ or\%5B5\%2C1\%5D\%7CJurisdicci\%F3n\%5B5\%2C1\%5D\%7CTribunal\%5 B5\%2C1\%5D \%7CPublicaci\%F3n\%5B5\%2C1\%5D\%7CColecci\%F3n\%20 
tem\%E1tica\%5B5\%2C1\%5D\%7CTipo\%20de\%20Documento/Doctrina\&t=30>. [Consultado el 14/10/2018].

MICHALEWICZ A., «Atención en Salud Mental de los niños, niñas y adolescentes alojados en hogares (Ongs) en la Ciudad de Buenos Aires. Problemáticas complejas e intervenciones posibles a partir de la articulación intersectorial», en BLANCK, E., Dialogo Abierto acerca del Estado de implementación de la Ley 26061, Buenos Airees (Eudeba), 2011, pp. 49-67.

PAGANO, L., «Internaciones por causa de salud mental», Revista de Actualidad Derecho de Familia en el Código Civil y Comercial, núm. 6, 2017, pp.171-190.

PALACIOS, A., El modelo social de discapacidad: orígenes, caracterización y plasmación de la Convención Internacional sobre los Derechos de las Personas con Discapacidad. Madrid (Grupo Editorial CINCA), 2008.

PALACIOS, A., «A modo de introducción. La Salud Mental como cuestión de Derechos Humanos», en HERRERA, M.; LLOVERAS, N. y KEMELMAJER DE CARLUCCI, A. (dirs.), Máximos Precedentes. Derecho de Familia, Tomo IV, Buenos Aires (La Ley), 2014, pp. 643-764.

SARQUIS, L., «Las personas con discapacidad y su participación en el proceso de determinación de la capacidad ¿obstáculos diferenciados en su perjuicio?», Derecho de Familia. Revista Interdisciplinaria de Doctrina y Jurisprudencia, núm. 84, 2018, pp. 119-130. 